\title{
ÉPOCAS DE SEMEADURA DE TRITICALE EM CAPÃO BONITO, SP'1
}

\author{
JOÃO CARLOS FELICIO², CARLOS EDUARDO OLIVEIRA CAMARGO3, \\ JAIRO LOPES DE CASTRO 4 E MARCELO BENTO PAES DE CAMARGO ${ }^{3}$
}

\begin{abstract}
RESUMO - O objetivo do trabalho foi avaliar o rendimento de grãos, o peso hectolítrico e o peso de mil sementes de dez genótipos de triticale e dois genótipos de trigo, em três épocas de semeadura. O experimento foi instalado na Estação Experimental de Capão Bonito, região sudoeste do Estado de São Paulo, no qüinqüênio 1991-95. Estudou-se a disponibilidade hídrica do solo, mediante balanços hídricos decendiais, considerando $100 \mathrm{~mm}$ como capacidade de retenção de água no solo. Os resultados indicaram a primeira época como a melhor para os parâmetros estudados, e a terceira época não deve ser recomendada. Com relação ao rendimento de grãos, destacaram-se, nas três épocas, os genótipos IAC2 e BGL"S"/CIN"S"/MUS"S". Os genótipos IAC 3, Hare 212, Ardilla"S" e ICT 8803 apresentaram-se produtivos na segunda e terceira épocas, e o genótipo MERINOS"S"/JO"S"/3/BGL"S"/CIN"S"/MUS"S", somente na terceira época. O melhor genótipo, independentemente de época, foi o IAC 2. O rendimento de grãos está associado positivamente com o peso de mil sementes. A ocorrência dos agentes causais de manchas foliares foi mais intensa no genótipo de trigo IAC 24 do que nos genótipos de triticales, excetuando-se o CEP 15 .
\end{abstract}

Termos para indexação: genótipo, trigo, sementes, balanço hídrico, doenças.

\section{SEEDING TIMES OF TRITICALE IN CAPÃO BONITO, SP}

\begin{abstract}
Ten triticale and two wheat genotypes were evaluated at three seeding times $\left(21^{\text {st }}\right.$ to $31^{\text {st }}$ of March, $11^{\text {th }}$ to $20^{\text {th }}$ of April and $21^{\text {st }}$ to $31^{\text {st }}$ of May) for grain yield, test weight and 1,000 grain weight in experiments carried out at Capão Bonito Experiment Station (SP, Brazil), in the period 1991-95. Soil water availability was obtained by water balances taken at ten days intervals considering $100 \mathrm{~mm}$ as the soil retention capacity. The results indicated that the first seeding time was the best for the evaluated parameters. In relation to grain yield genotypes IAC 2 and BGL"S"/CIN"S"//MUS"S" presented good performance at the three seeding times. The genotypes IAC 3, Hare 212, Ardilla"S" and ICT 8803 showed high production at $2^{\text {nd }}$ and $3^{\text {rd }}$ seeding times and the genotype MERINOS"S"/JO"S"/3/BGL"S"/ CIN"S"/MUS"S" only at the $3^{\text {rd }}$ seeding time. The best genotype was IAC 2 , independent of the seeding time. Grain yield was associated with 1,000 grain weight. The occurrence of the causal agents of leaf spots was more intense in leaves of the wheat genotype IAC 24 than in triticales except for CEP 15.
\end{abstract}

Index terms: grain yield, wheat genotype, hydric balance, diseases.

\section{INTRODUÇÃO}

Kalckmann et al. (1965) definiram que todas as áreas tritícolas mundiais apresentam em comum

\footnotetext{
${ }^{1}$ Aceito para publicação em 5 de maio de 1999.

${ }^{2}$ Eng. Agr., Instituto Agronômico (IAC), Caixa Postal 28, CEP 13001-970 Campinas, SP. E-mail: jfelicio@cec.iac.br

${ }^{3}$ Eng. Agr., Ph.D., IAC. Bolsista do CNPq. E-mail: mcamargo@cec.br

${ }^{4}$ Eng. Agr., M.Sc., IAC. Bolsista do CNPq
}

regiões com grande variação anual de temperatura e onde são relativamente escassas as precipitações pluviais.

O triticale chegou aos agricultores um século depois de os primeiros cruzamentos férteis terem sido estudados, e, por conter os genomas do trigo e do centeio, tem potencial para combinar características favoráveis das duas espécies. Sua principal utilização é em regiões marginais às do cultivo de outros cereais de inverno, e apresenta rendimentos elevados, resistência às doenças e tolerância a solos ácidos (Baier, 1995). 
A maior potencialidade quanto ao desenvolvimento da cultura do triticale encontra-se em áreas menos adequadas ao cultivo de outros cereais de inverno: em solos ácidos do sul do Brasil, na Polônia, Rússia, África do sul e no sul dos Estados Unidos e climas semi-áridos, da Austrália, Argentina, México, Estados Unidos e Rússia, e altiplanos do Peru, Colômbia, México e Turquia (Kohli, 1989).

O comportamento agronômico de cultivares de triticale e de trigo no Estado de São Paulo em condições de sequeiro e irrigados por aspersão foi avaliado por Felicio et al. (1990b, 1993), que estudaram cultivares de triticale de ampla adaptação regional, rendimento de grãos superiores, baixo peso hectolítrico $(\mathrm{PH})$, boa resistência à ferrugem-da-folha e suscetibilidade à helmintosporiose.

Em solos de várzea, as cultivares de triticale se adaptaram melhor que as de trigo, pois ocorreu o chochamento das espigas do trigo durante o florescimento (Felicio \& Leite, 1982).

A cultura do trigo na região sul do Estado de São Paulo apresenta grande variação de produtividade quando semeada em abril, pelo fato de o florescimento coincidir com períodos mais frios do ano e, portanto, apresentar maior possibilidade de perdas pelas geadas (Felicio et al., 1986).

Estudos desenvolvidos por Felicio et al. (1988, 1990a, 1991), para determinação das melhores épocas de semeadura de trigo em São Paulo, com base na produtividade de grãos e na probabilidade do atendimento da demanda hídrica, mostraram que as melhores épocas de semeadura são no terceiro decêndio do mês de março e início de abril (primeiro decêndio).

Este trabalho foi realizado para estudar o efeito de épocas de semeadura sobre o desempenho agronômico de genótipos de triticale de diferentes grupos bioclimáticos, e de trigo.

\section{MATERIAL E MÉTODOS}

Foram estudados dez genótipos de triticale e dois genótipos de trigo, em três épocas de semeadura: terceiro decêndio do mês de março; o segundo decêndio de abril e o terceiro decêndio de maio, respectivamente, abrangendo o período de 1991-95, no município de Capão Bonito, região sul do Estado de São Paulo, localizado na latitude de $24^{\circ} 2^{\prime} \mathrm{S}$, longitude $482^{\circ} 22^{\prime} \mathrm{W}$ e altitude de $702 \mathrm{~m}$.
Os genótipos de triticale foram divididos em grupos bioclimáticos quanto ao ciclo vegetativo da emergência à maturação, sendo considerados: superprecoce, com ciclo de até 120 dias: CEP 15 (Panda); ciclo precoce, com maturação de 121 a 130 dias: IAC 3 (B-8285-163-1Y2Y-2M-OY-12M-2Y-4M-OY) e Ardilla"S" (CTM-13973$1 \mathrm{Y}-11 \mathrm{Y}-1 \mathrm{M}-\mathrm{OY})$; ciclo médio, com maturação de 131 a 140 dias: IAC 1 (Juanillo), MERINOS"S"/JLO"S"/3/ BGL"S"/CIN"S"//MUS"S" (B8413-OM-3M-OY), IAC 2 (Tejon/Beagle X16134), Hare 212 e BGL"S"/ RAM"S"; e de ciclo tardio, acima de 140 dias: BGL"S"/ CIN"S"//MUS"S" e ICT 8803 (M2A/KLA"S"//MA). Os genótipos de trigo utilizados, considerados de ciclo médio (131 a 140 dias), foram: IAC 24 (IAS 51/IRN 597-70) e IAC 60 ( IRN 33-70 / IAC 5).

$\mathrm{Na}$ adubação, foram utilizados $30 \mathrm{~kg}$ de N, $90 \mathrm{~kg}$ de $\mathrm{P}_{2} \mathrm{O}_{5}$ e $20 \mathrm{~kg}$ de $\mathrm{K}_{2} \mathrm{O}$ por hectare, respectivamente, sob a forma de sulfato de amônio com $20 \%$ de N, superfosfato simples com $20 \%$ de $\mathrm{P}_{2} \mathrm{O}_{5}$ e cloreto de potássio com $60 \%$ de $\mathrm{K}_{2} \mathrm{O}$, aplicados no sulco da semeadura, de acordo com as tabelas de adubação e calagem do Instituto Agronômico (Raij et al., 1985). Não foi realizada adubação de cobertura.

O delineamento estatístico empregado foi o de blocos ao acaso, com quatro repetições por época, no mesmo local.

As parcelas de cada experimento foram constituídas de seis linhas de $3 \mathrm{~m}$ de comprimento, com espaçamento de $0,20 \mathrm{~m}$, deixando-se um espaço lateral entre cada parcela de $0,60 \mathrm{~m}$ e de $1 \mathrm{~m}$ entre blocos. A densidade de semeadura foi feita na base de 80 sementes viáveis por metro linear de sulco, equivalendo a 400 sementes por metro quadrado.

Para o cálculo da disponibilidade hídrica nas culturas do triticale e trigo no período 1991 a 1995, utilizou-se o balanço hídrico decendial, segundo o método de Thornthwaite \& Mather (1955). Os balanços hídricos foram elaborados considerando-se uma capacidade de retenção de água no solo de $100 \mathrm{~mm}$. Apesar de não representarem necessariamente a disponibilidade real de água no solo, tais balanços hídricos possibilitam boa caracterização das condições hídricas reinantes durante os períodos estudados. Os dados foram obtidos no posto meteorológico da Estação Experimental de Capão Bonito do Instituto Agronômico. A representação gráfica dos resultados do balanço hídrico (Figs. 1 a 5) foi feita pela técnica do extrato do balanço hídrico segundo Camargo \& Camargo (1993), que considera apenas os períodos com deficiência e excedente hídrico.

O comportamento dos genótipos com relação às doenças (manchas nas folhas) causadas pelo complexo 
helmintosporiose mais septoriose (Helminthosporium $\mathrm{sp}$ e Septoria sp.) foi caracterizado pela porcentagem de área foliar infectada, nas folhas superiores das plantas. Foi utilizada a escala de 0 a 99, em que zero significa imune; $1 \%$ a $5 \%$, resistente; $6 \%$ a $25 \%$, moderadamente resistente; $26 \%$ a $50 \%$, suscetível; e $51 \%$ a $99 \%$, altamente suscetível (Metha, 1978)

Foram avaliados o rendimento de grãos, peso de mil sementes e o peso hectolítrico, e os resultados foram submetidos à análise de grupos de experimentos em blocos ao acaso ( Pimentel-Gomes, 1970). A comparação das médias foi feita pelo teste de Duncan a 5\%, e utilizou-se o método de Eberhart \& Russell (1966), para avaliar a estabilidade e adaptabilidade dos genótipos de triticale e trigo.
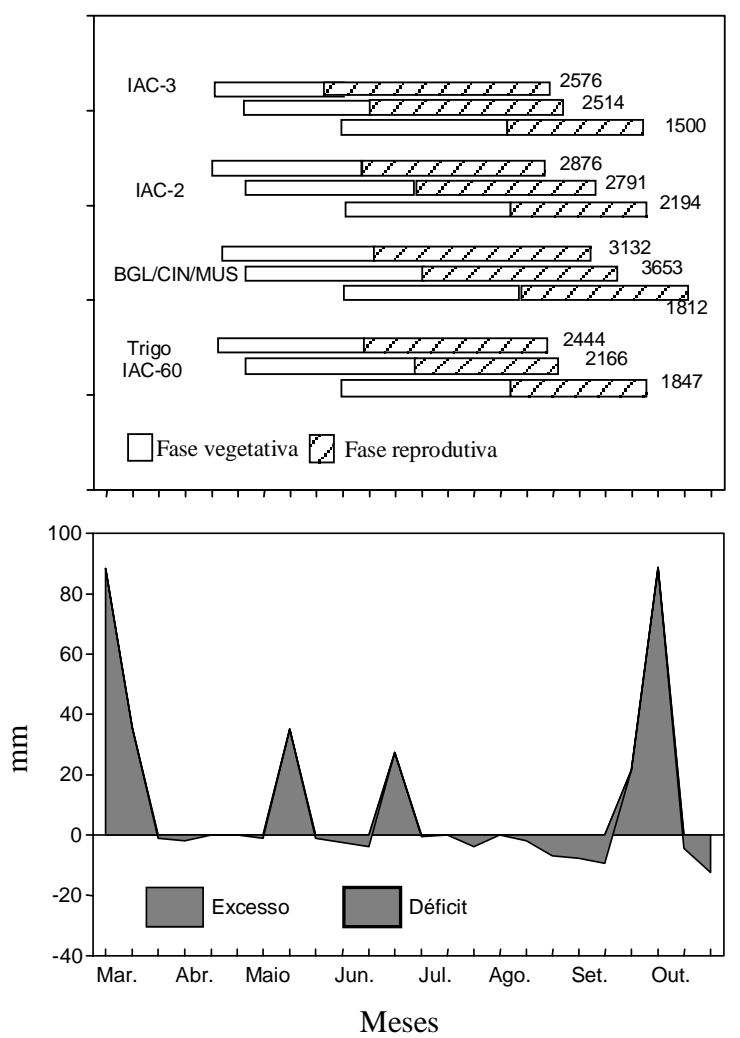

FIG. 1. Balanço hídrico decendial, pelo método de Thornthwaite \& Mather (1955) $(100 \mathrm{~mm})$ duração das fases fenológicas e rendimento (kg/ha) dos genótipos de triticale IAC-3, IAC-2 e BGL"S"/CIN"S"//MUS"S" e do genótipo de trigo IAC-60 em Capão Bonito, SP, 1991.

\section{RESULTADOS E DISCUSSÃo}

Os balanços hídricos decendiais referentes aos meses de março a outubro, período de 1991-95, na localidade de Capão Bonito, são apresentados nas Figs. 1 a 5 . Esses balanços permitem observar os períodos com excedente e deficiência hídrica. Durante os anos de 1991 e 1993, as precipitações pluviais apresentaram-se intercaladas com períodos de baixas deficiências hídricas, sendo que o mês de junho apresentou-se com excedente hídrico considerável para a época.

Nos meses de março e abril de 1992, houve excesso hídrico. Esse ano não apresentou excedente hídrico de maio a agosto, porém as poucas chuvas
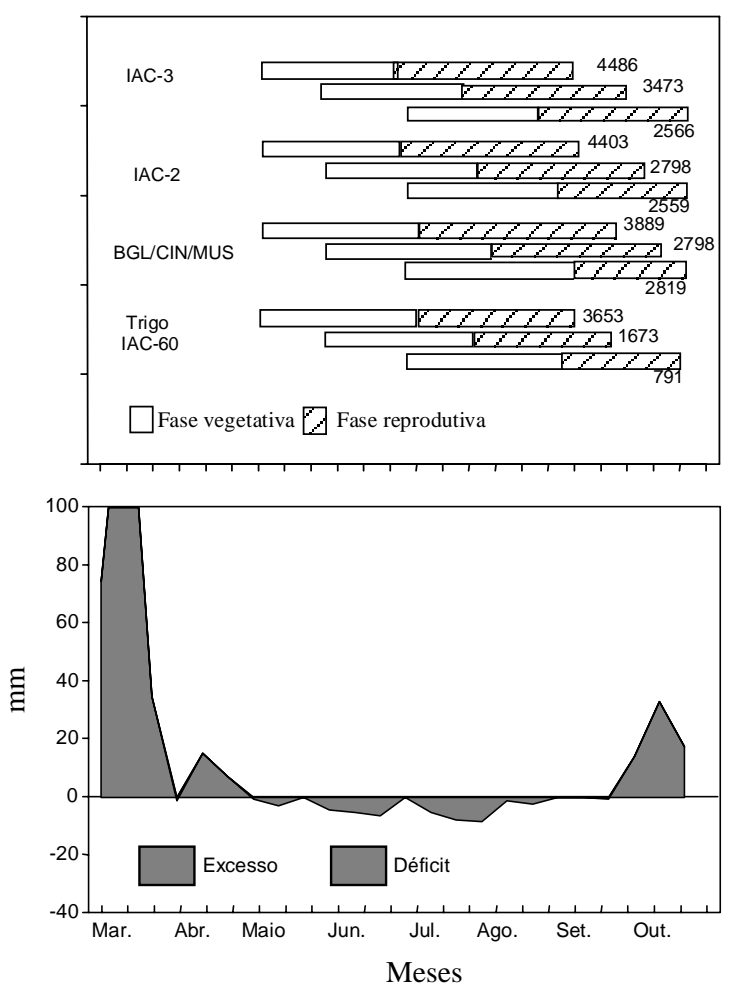

FIG. 2. Balanço hídrico decendial, pelo método de Thornthwaite \& Mather (1955) (100 mm), duração das fases fenológicas e rendimento (kg/ha) dos genótipos de triticale IAC-3, IAC-2 e BGL"S"/CIN"S"//MUS"S" e do genótipo de trigo IAC-60 em Capão Bonito, SP, 1992.

Pesq. agropec. bras., Brasília, v.34, n.12, p.2193-2202, dez. 1999 
ocorridas no final de junho permitiram reposição de água no solo, o que proporcionou produtividades elevadas.

O ano de 1994 mostrou-se atípico, com períodos longos de deficiência hídrica nos meses de abril a outubro, em especial nos meses de agosto-setembro. Este período de elevada deficiência hídrica condicionou produtividades inferiores para as semeaduras tardias.

A análise de variância conjunta para rendimentos médios de grãos (Tabela 1) revelou um valor de $\mathrm{F}$ significativo $(p<0,05)$ com relação a épocas, anos, genótipos e a interação anos $\mathrm{x}$ épocas, anos $\mathrm{x}$ genótipos e épocas $\mathrm{x}$ genótipos e anos $\mathrm{x}$ épocas $\mathrm{x}$ genótipos.
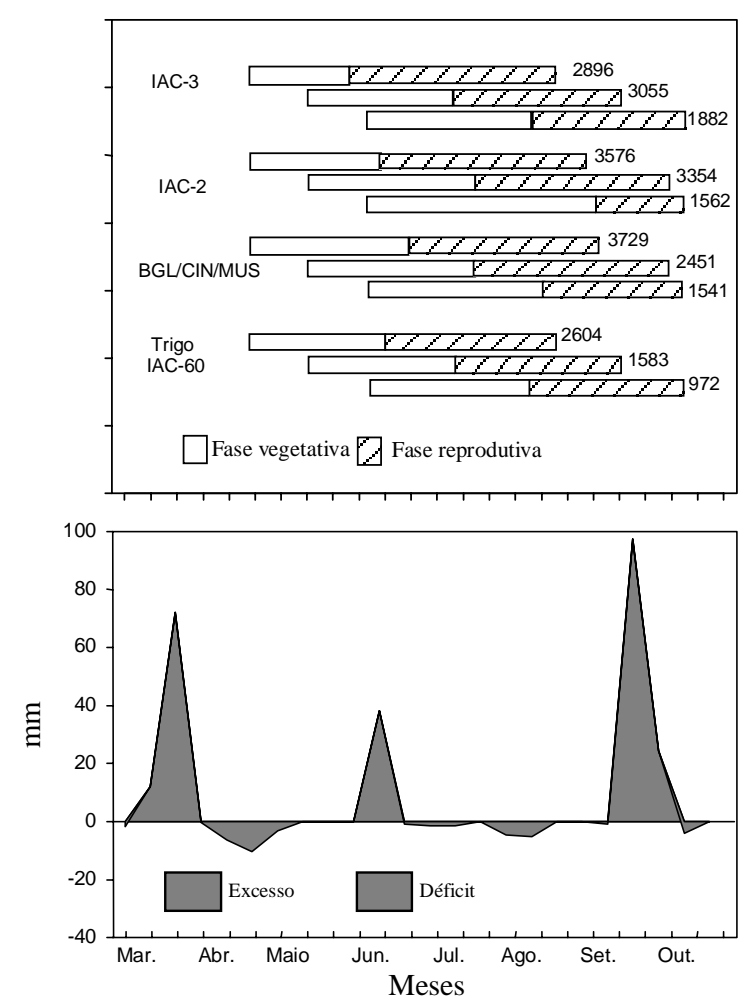

FIG. 3. Balanço hídrico decendial, pelo método de Thornthwaite \& Mather (1955) $(100 \mathrm{~mm})$, duração das fases fenológicas e rendimento (kg/ha) dos genótipos de triticale IAC-3, IAC-2 e BGL"S"/CIN"S"//MUS"S" e do genótipo de trigo IAC-60 em Capão Bonito, SP, 1993.
Na comparação de médias entre épocas de semeadura, independentemente de genótipos, a primeira época diferiu da segunda, e esta, por sua vez, foi diferente da terceira, pelo teste de Duncan a 5\% de probabilidade. Na comparação de rendimentos médios entre genótipos, em cada época, verificou-se uma superioridade do IAC 2 em relação aos dos outros genótipos.

Para a comparação de rendimentos médios de grãos, independentemente de época, destacaram-se os genótipos IAC 2 (2.551 kg/ha) e BGL"S"/CIN"S"// MUS"S" (2.470 kg/ha), com produtividade mais elevada na média dos cinco anos.

$\mathrm{Na}$ análise do comportamento produtivo dos genótipos em cada época, verificou-se que na pri-
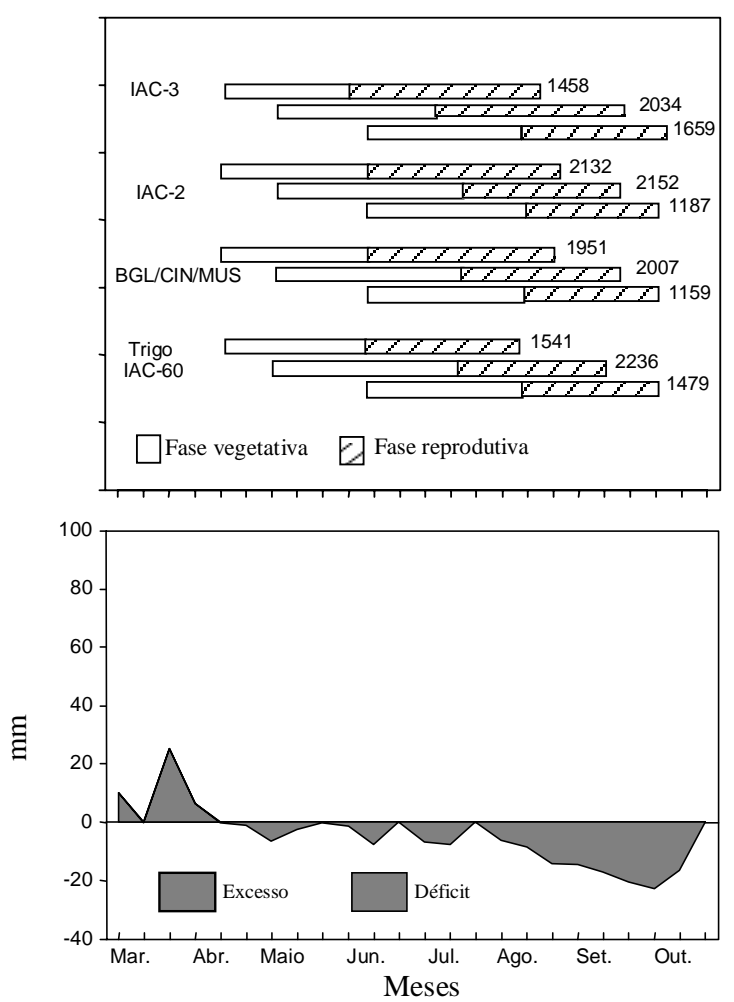

FIG. 4. Balanço hídrico decendial, pelo método de Thornthwaite \& Mather (1955) (100 mm), duração das fases fenológicas e rendimento (kg/ha) dos genótipos de triticale IAC-3, IAC-2 e BGL"S"/CIN"S"//MUS"S" e do genótipo de trigo IAC-60 em Capão Bonito, SP, 1994. 
meira época (terceiro decêndio de março) os genótipos IAC 2, BGL"S"/CIN"S"//MUS"S" e IAC 3 foram estatisticamente diferentes dos demais genótipos, exceto o Hare 212, que foi igual ao IAC 3.

$\mathrm{Na}$ semeadura da segunda época (segundo decêndio de abril), o rendimento dos genótipos Ardilla "S", Hare 212 e ICT 8803 foi similar estatisticamente ao do IAC 2, BGL"S"/CIN"S"//MUS"S" e IAC 3. As condições meteorológicas favoráveis ocorridas no período da emergência e, posteriormente, do espigamento à plena floração, favoreceram os genótipos de ciclos médios/tardios.

Na última época de semeadura (terceiro decêndio de maio), os rendimentos dos genótipos de um modo
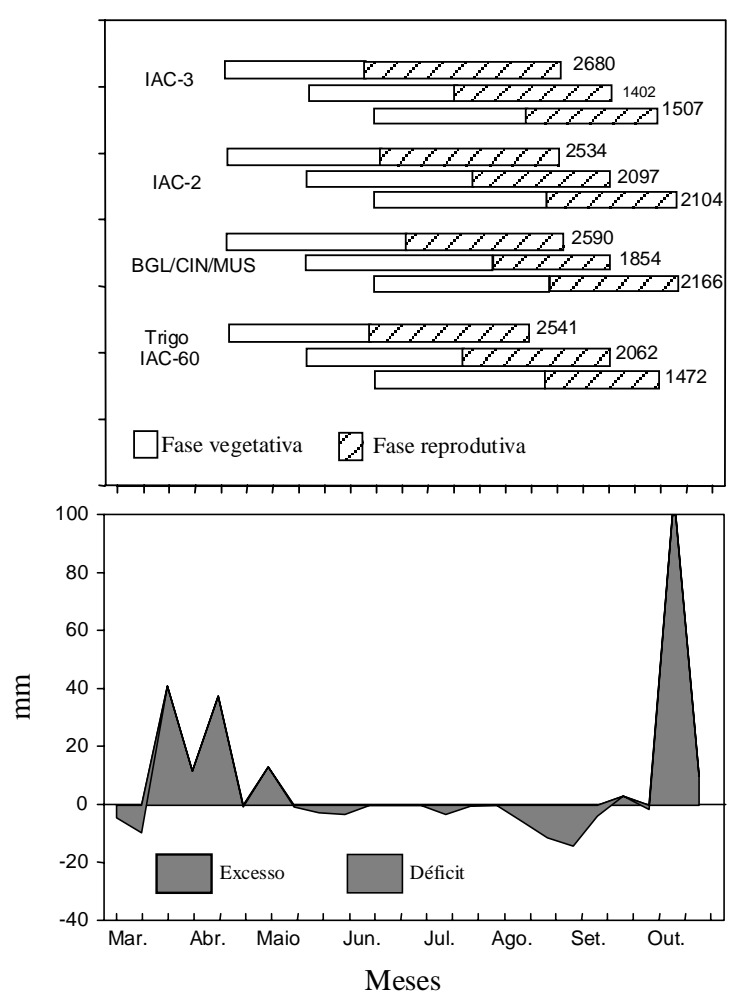

FIG. 5. Balanço hídrico decendial, pelo método de Thornthwaite \& Mather (1955) $(100 \mathrm{~mm})$ duração das fases fenológicas e rendimento $(\mathrm{kg} / \mathrm{ha})$ dos genótipos de triticale IAC-3, IAC-2 e BGL"S"/CIN"S"//MUS"S" e do genótipo de trigo IAC-60 em Capão Bonito, SP, 1995. geral foram inferiores aos obtidos nas outras épocas. Os genótipos Hare 212, Ardilla "S", MERINOS"S"/JLO"S"/3/BGL"S"/CIN"S"//MUS"S" e ICT 8803 não diferiram de IAC 2, BGL"S"/CIN"S"// MUS"S" e IAC 3, que foram os mais produtivos. Nessa época, as precipitações pluviais no período maio-outubro foram muito baixas, principalmente, nos meses de junho a agosto, afetando, portanto, neste período de semeadura, a fase que vai do emborrachamento ao enchimento de grãos, o que contribuiu para diminuir o rendimento de grãos dos genótipos. As baixas precipitações pluviais nos meses de junho a agosto são características principais dessa região, e ocasionam disponibilidade hídrica baixa, de acordo com as Figs. 1 a 5 .

Os dados médios dos cinco anos revelaram um rendimento de $2.436 \mathrm{~kg} / \mathrm{ha}(100 \%)$ quanto à semeadura dos genótipos na primeira época, $2.262 \mathrm{~kg} / \mathrm{ha}$ $(92,86 \%)$ na segunda época, e de $1.609 \mathrm{~kg} / \mathrm{ha}$ $(66,05 \%)$ na terceira época.

A interação entre épocas e genótipos foi significativa $(p<0,05)$, os genótipos apresentaram comportamentos específicos em cada época no decorrer do período. Sendo assim, na primeira época destacaram-se o IAC 2 e BGL"S"/CIN"S"//MUS"S". Na segunda época, além dos genótipos IAC 2 e BGL"S"/CIN"S"//MUS"S", destacaram-se os genótipos IAC 3, Hare 212, Ardilla"S" e ICT 8803, e na terceira época, os genótipos citados da segunda época e o MERINOS"S"/JLO"S"/3/BGL"S"/CIN"S"// MUS"S".

O genótipo de trigo IAC 60 apresentou-se superior ao IAC 24, mas ambos apresentaram rendimentos inferiores aos dos genótipos de triticale na média das três épocas, com exceção do CEP 15. Este genótipo de triticale, de ciclo superprecoce, apresentou o menor rendimento de grãos entre os triticales, no período de experimentação, o que confirma as observações de Felicio et al. (1988, 1990a).

Quanto à comparação para determinar a melhor época para cada cultivar (Tabela 1), verificou-se que, de um modo geral, os genótipos apresentaram rendimentos maiores na primeira época, com exceção dos genótipos ICT 8803 e o CEP 15, que apresentaram melhor desempenho na segunda época.

A análise conjunta das épocas referente ao peso hectolítrico (Tabela 2) apresentou efeitos significati- 
$\operatorname{vos}(p<0,05)$ no tocante às fontes de variação anos, épocas, genótipos, interações anos x genótipos, anos $\mathrm{x}$ épocas, épocas $\mathrm{x}$ genótipos $\mathrm{e}$ a anos $\mathrm{x}$ épocas $\mathrm{x}$ genótipos. As médias da primeira e segunda época, independentemente de genótipos, não diferiram entre si, sendo a terceira época a que apresentou menor valor, diferindo, portanto, das outras duas, pelo teste de Duncan a 5\%. O genótipo de trigo IAC 24 apresentou melhor índice nas três épocas, e entre os genótipos de triticale destacaram-se Ardilla"S", Hare 212 e IAC 3.

Efeitos altamente significativos ( $\mathrm{P}<0,01)$ ocorreram em relação a anos, épocas e genótipos e em relação às interações anos x épocas, épocas x genótipos, anos $\mathrm{x}$ genótipos e anos $\mathrm{x}$ épocas $\mathrm{x}$ genótipos na avaliação do peso de mil sementes (Tabela 3). Na primeira época, independentemente do fator genótipo, ocorreram pesos de mil sementes

TABELA 1. Rendimento médio (kg/ha), de grãos dos genótipos de triticale e trigo em três época de semeadura, no município de Capão Bonito (SP), no qüinqüênio 1991-95².

\begin{tabular}{lcccc}
\hline Genótipos & $1^{\mathrm{a}}$ época & $2^{\mathrm{a}}$ época & $3^{\mathrm{a}}$ época & Médias \\
\hline IAC 2 & $3094 \mathrm{a}$ & $2639 \mathrm{a}$ & $1921 \mathrm{a}$ & $2551 \mathrm{a}$ \\
BGL"S"/CIN"S"//MUS"S" & $2958 \mathrm{ab}$ & $2552 \mathrm{ab}$ & $1900 \mathrm{a}$ & $2470 \mathrm{ab}$ \\
IAC 3 & $2819 \mathrm{bc}$ & $2496 \mathrm{ab}$ & $1823 \mathrm{a}$ & $2379 \mathrm{bc}$ \\
Hare 212 & $2707 \mathrm{~cd}$ & $2397 \mathrm{ab}$ & $1741 \mathrm{ac}$ & $2282 \mathrm{c}$ \\
Ardilla "S" & $2527 \mathrm{de}$ & $2439 \mathrm{ab}$ & $1800 \mathrm{ab}$ & $2255 \mathrm{~cd}$ \\
BGL"S"/RAM"S" & $2498 \mathrm{de}$ & $2323 \mathrm{bc}$ & $1528 \mathrm{~cd}$ & $2117 \mathrm{de}$ \\
MERINOS"S"/JLO"S"/3/BGL"S"/CIN"S"//MUS"S" & $2516 \mathrm{de}$ & $2122 \mathrm{~cd}$ & $1709 \mathrm{ac}$ & $2116 \mathrm{de}$ \\
IAC 1 & $2443 \mathrm{e}$ & $2314 \mathrm{bc}$ & $1551 \mathrm{bd}$ & $2102 \mathrm{e}$ \\
ICT 8803 & $2179 \mathrm{f}$ & $2376 \mathrm{ab}$ & $1668 \mathrm{ac}$ & $2074 \mathrm{e}$ \\
IAC 60 (trigo) & $2557 \mathrm{de}$ & $1944 \mathrm{~d}$ & $1312 \mathrm{de}$ & $1938 \mathrm{f}$ \\
IAC 24 (trigo) & $1943 \mathrm{~g}$ & $1880 \mathrm{de}$ & $1250 \mathrm{e}$ & $1691 \mathrm{~g}$ \\
CEP 15 & $993 \mathrm{~h}$ & $1659 \mathrm{e}$ & $1107 \mathrm{e}$ & $1253 \mathrm{~h}$ \\
Médias & $2436 \mathrm{~A}$ & $2262 \mathrm{~B}$ & $1609 \mathrm{C}$ & \\
\hline
\end{tabular}

${ }^{1}$ Médias seguidas por letras distintas, minúsculas na coluna e maiúsculas na linha, diferem entre si pelo teste de Duncan a 5\%; F ano: 55,93* F época: 237,47*; F genótipo: 51,36*; F ano x época: 29,07*; F ano x genótipo: 5,34*; F genótipo x época: 5,80*; F ano x época x genótipo: 2,83*; CV (\%) ano: 4,96; CV (\%) época: 6,01; CV (\%) genótipo: 18,25.

TABELA 2. Peso (kg) hectolítrico dos genótipos de triticale e trigo em três época de semeadura, no município de Capão Bonito (SP), no qüinqüênio 1991-951.

\begin{tabular}{lllll}
\hline Genótipos & $1^{\text {a }}$ época & $2^{\text {a }}$ época & $3^{\text {a época }}$ & Médias \\
\hline IAC 2 & $63,02 \mathrm{f}$ & $60,94 \mathrm{~g}$ & $58,80 \mathrm{~h}$ & $60,92 \mathrm{f}$ \\
BGL"S"/CIN"S"//MUS"S" & $68,87 \mathrm{~cd}$ & $68,22 \mathrm{de}$ & $64,62 \mathrm{ef}$ & $67,19 \mathrm{~d}$ \\
IAC 3 & $69,95 \mathrm{bd}$ & $69,24 \mathrm{~cd}$ & $68,72 \mathrm{bc}$ & $69,31 \mathrm{c}$ \\
Hare 212 & $70,77 \mathrm{bc}$ & $70,27 \mathrm{bd}$ & $66,91 \mathrm{~cd}$ & $69,32 \mathrm{c}$ \\
Ardilla "S" & $69,97 \mathrm{bc}$ & $71,75 \mathrm{~b}$ & $69,79 \mathrm{~b}$ & $70,54 \mathrm{~b}$ \\
BGL"S"/RAM"S" & $60,17 \mathrm{~g}$ & $60,20 \mathrm{~g}$ & $57,82 \mathrm{~h}$ & $59,40 \mathrm{~g}$ \\
MERINOS"S"/JLO"S"/3/BGL"S"/CIN"S"//MUS"S" & $67,40 \mathrm{~d}$ & $66,72 \mathrm{e}$ & $64,43 \mathrm{ef}$ & $66,52 \mathrm{~d}$ \\
IAC 1 & $65,21 \mathrm{e}$ & $64,62 \mathrm{f}$ & $62,47 \mathrm{fg}$ & $64,10 \mathrm{e}$ \\
ICT 8803 & $64,79 \mathrm{ef}$ & $63,40 \mathrm{f}$ & $61,22 \mathrm{~g}$ & $63,14 \mathrm{e}$ \\
IAC 60 (t) & $71,85 \mathrm{ab}$ & $71,02 \mathrm{bc}$ & $67,56 \mathrm{~cd}$ & $70,14 \mathrm{bc}$ \\
IAC 24 (t) & $73,31 \mathrm{a}$ & $76,68 \mathrm{a}$ & $74,56 \mathrm{a}$ & $74,85 \mathrm{a}$ \\
CEP 15 & $63,82 \mathrm{ef}$ & $68,84 \mathrm{~d}$ & $66,07 \mathrm{de}$ & $66,24 \mathrm{~d}$ \\
Médias & $67,51 \mathrm{~A}$ & $67,67 \mathrm{~A}$ & $65,23 \mathrm{~B}$ & \\
\hline
\end{tabular}

1 Médias seguidas por letras distintas, minúsculas na coluna e maiúsculas na linha, diferem entre si pelo teste de Duncan a 5\%. F ano: 103,58*; F época: 47,37*; F genótipo: 111,09*; F ano x época: 31,72*; F ano x genótipo: 3,99*; F genótipo x época: 3,38*; F ano x época x genótipo: 2,38*; CV (\% ) ano: 0,849; CV (\%) )época: 1,32; CV (\%) genótipo: 4,84 
maiores em relação às outras duas épocas, diferindo das demais pelo teste de Duncan a 5\%. Os genótipos de triticale, com exceção do CEP 15, apresentaram melhores índices de peso de mil sementes do que os genótipos de trigo na média das três épocas - observação feita por Felicio et al. (1990a). Destacaram-se Ardilla"S", IAC 2, IAC-1, BGL"S"/CIN"S"//MUS"S", IAC 3 e MERINOS"S"/JLO"S"/3/BGL"S"/CIN"S"// MUS"S".
A ocorrência de manchas-foliares causadas por doenças fúngicas Helminthosporium sp. e Septoria nodorum Bek e Septoria tritici Rob.ex Desm. ficaram generalizadas durante o período estudado (Tabela 4), concentrando-se principalmente nas duas primeiras épocas. Observou-se que as manchas foliares nas plantas de trigo foram muito mais intensas na semeadura de 1995 (primeira e segunda época). Essas observações coincidiram com as pre-

TABELA 3. Peso (g) de mil sementes dos genótipos de triticale e trigo e resumo das análises de variâncias dos experimentos, estudados em três época de semeadura, no município de Capão Bonito (SP), no qüinqüênio 1991-951.

\begin{tabular}{lllll}
\hline Genótipos & $1^{\mathrm{a}}$ época & $2^{\mathrm{a}}$ época & $3^{\mathrm{a}}$ época & Médias \\
\hline IAC 2 & $40,59 \mathrm{~b}$ & $39,02 \mathrm{~b}$ & $35,90 \mathrm{~b}$ & $38,50 \mathrm{~b}$ \\
BGL"S"/CIN"S"//MUS"S" & $39,44 \mathrm{bc}$ & $38,44 \mathrm{bd}$ & $34,70 \mathrm{bd}$ & $37,53 \mathrm{bd}$ \\
IAC 3 & $37,64 \mathrm{c}$ & $38,70 \mathrm{~cd}$ & $34,78 \mathrm{bd}$ & $37,01 \mathrm{ce}$ \\
Hare 212 & $39,31 \mathrm{bc}$ & $36,90 \mathrm{~cd}$ & $33,85 \mathrm{ce}$ & $36,69 \mathrm{ce}$ \\
Ardilla "S" & $42,36 \mathrm{a}$ & $41,42 \mathrm{a}$ & $39,96 \mathrm{a}$ & $40,91 \mathrm{a}$ \\
BGL"S"/RAM"S" & $39,32 \mathrm{bc}$ & $36,83 \mathrm{~d}$ & $32,15 \mathrm{e}$ & $36,10 \mathrm{e}$ \\
MERINOS"S"/JLO"S"/3/BGL"S"/CIN"S"//MUS"S" & $39,66 \mathrm{~b}$ & $38,84 \mathrm{~b}$ & $33,08 \mathrm{bc}$ & $37,86 \mathrm{bc}$ \\
IAC 1 & $39,02 \mathrm{bc}$ & $38,16 \mathrm{bd}$ & $35,95 \mathrm{~b}$ & $37,71 \mathrm{bd}$ \\
ICT 8803 & $35,43 \mathrm{~d}$ & $34,25 \mathrm{e}$ & $31,98 \mathrm{e}$ & $33,89 \mathrm{f}$ \\
IAC 60 (trigo) & $37,65 \mathrm{c}$ & $34,36 \mathrm{e}$ & $32,39 \mathrm{e}$ & $34,80 \mathrm{f}$ \\
IAC 24 (trigo) & $34,24 \mathrm{~d}$ & $34,20 \mathrm{e}$ & $33,14 \mathrm{de}$ & $33,86 \mathrm{f}$ \\
CEP 15 & $25,60 \mathrm{e}$ & $30,92 \mathrm{f}$ & $27,56 \mathrm{f}$ & $28,01 \mathrm{~g}$ \\
Médias & $37,52 \mathrm{~A}$ & $36,84 \mathrm{~B}$ & $33,86 \mathrm{C}$ & \\
\hline
\end{tabular}

1 Médias seguidas por letras distintas, minúsculas na coluna e maiúsculas na linha, diferem entre si pelo teste de Duncan a 5\%. F ano: 212,69* F época: 93,06*; F genótipo: 80,93*; $\mathrm{F}$ ano $\mathrm{x}$ época: 42,66*; $\mathrm{F}$ ano $\mathrm{x}$ genótipo: 6,70*; $\mathrm{F}$ genótipo $\mathrm{x}$ época: 4,92*; $\mathrm{F}$ ano $\mathrm{x}$ época $\mathrm{x}$ genótipo: 2,75*; CV (\%) ano: 0,779; CV (\%) época: 2,50; CV (\%) genótipo: 7,70.

TABELA 4. Índices de ocorrência de doenças que causam manchas foliares ${ }^{1} \mathrm{em}$ porcentagem de área foliar infectada, em três épocas de semeadura, dos genótipos de triticale e trigo, no município de Capão Bonito, SP, no qüinqüênio 1991-95.

\begin{tabular}{|c|c|c|c|c|c|c|c|c|c|c|c|c|c|c|c|c|c|c|}
\hline \multirow[t]{2}{*}{ Genótipos } & \multicolumn{6}{|c|}{$1^{\mathrm{a}}$ época } & \multicolumn{6}{|c|}{$2^{\mathrm{a}}$ época } & \multicolumn{6}{|c|}{$3^{\mathrm{a}}$ época } \\
\hline & 91 & 92 & 93 & 94 & 95 & Médias & 91 & 92 & 93 & 94 & 95 & Médias & 91 & 92 & 93 & 94 & 95 & Médias \\
\hline IAC 3 & 20 & 10 & 10 & 20 & 30 & 18 & 20 & 30 & 20 & 20 & 30 & 24 & 10 & 5 & 10 & 20 & 10 & 11 \\
\hline MERINOS"S"/.. & 20 & 50 & 20 & 20 & 40 & 30 & 20 & 20 & 10 & 20 & 40 & 22 & 10 & 5 & 10 & 10 & 5 & 8 \\
\hline IAC 2 & 20 & 30 & 10 & 20 & 40 & 24 & 20 & 5 & 10 & 10 & 30 & 15 & 10 & 5 & 10 & 10 & 5 & 8 \\
\hline BGL"S"/RAM"S" & 10 & 10 & 10 & 20 & 40 & 18 & 20 & 5 & 10 & 10 & 30 & 15 & 10 & 5 & 10 & 10 & 5 & 8 \\
\hline Ardillas "S" & 20 & 10 & 20 & 30 & 30 & 22 & 20 & 20 & 10 & 10 & 40 & 20 & 20 & 5 & 10 & 20 & 10 & 13 \\
\hline BGL"S"/CIN"S"/MUS"S" & 10 & 10 & 10 & 20 & 40 & 18 & 20 & 10 & 10 & 20 & 30 & 18 & 10 & 5 & 10 & 10 & 5 & 8 \\
\hline IAC 1 & 20 & 10 & 10 & 20 & 40 & 20 & 20 & 10 & 10 & 20 & 30 & 18 & 10 & 5 & 10 & 10 & 5 & 8 \\
\hline ICT 8803 & 10 & 30 & 10 & 20 & 30 & 20 & 20 & 5 & 10 & 20 & 30 & 17 & 10 & 5 & 10 & 10 & 5 & 8 \\
\hline IAC 60 & 20 & 20 & 30 & 30 & 20 & 24 & 20 & 20 & 20 & 30 & 30 & 24 & 10 & 5 & 10 & 10 & 5 & 8 \\
\hline IAC 24 & 30 & 30 & 30 & 40 & 50 & 36 & 30 & 20 & 30 & 40 & 40 & 32 & 30 & 10 & 20 & 20 & 10 & 18 \\
\hline CEP 15 & 40 & 50 & 50 & 30 & 50 & 44 & 60 & 30 & 30 & 40 & 50 & 42 & 30 & 10 & 20 & 20 & 10 & 18 \\
\hline HARE 212 & 20 & 10 & 10 & 20 & 30 & 18 & 30 & 5 & 10 & 20 & 30 & 23 & 10 & 5 & 10 & 10 & 10 & 9 \\
\hline
\end{tabular}

${ }^{1}$ Septoria sp. e Helminthosporium sp. 
cipitações mais freqüentes ocorridas entre os meses de março a maio. Não se verificou, portanto, resistência dos genótipos a estas doenças. Entretanto, menores incidências ocorreram quando as precipitações foram menos freqüentes, o que confirma as observações de Luz (1982) de que o período de umidificação pós-inoculação do fungo influi na resistência do genótipo.

Os genótipos de trigo IAC 24 e IAC 60 apresentaram susceptibilidade mais intensa aos agentes causais das manchas foliares do que os de triticale, com exceção do CEP 15. Com referência a este genótipo e aos genótipos de trigo, os índices de doenças das folhas provavelmente são a causa do baixo desempenho no período avaliado, mediante redução da área foliar fotossinteticamente ativa causada pela alta susceptibilidade às doenças foliares.

As associações entre os parâmetros rendimento de grãos, peso hectolítrico $(\mathrm{PH})$ e o peso de mil sementes (PMS) nas três épocas de semeadura, são apresentadas na Tabela 5. A correlação entre rendimento de grãos e peso de mil sementes nas três épocas $(r=0,89, r=0,83$ e $r=0,72)$ apresentou resultado significativo ( $<<0,01, p<0,01$ e $p<0,05$, respectivamente). A influência positiva do peso de mil sementes no rendimento de grãos também foi observado por Felicio et al. (1988). Entretanto, não houve cor- relação significativa $(p>0,05)$ entre rendimento $x$ peso hectolítrico e peso hectolítrico $\mathrm{x}$ peso de mil sementes.

$\mathrm{O}$ rendimento de grãos, o coeficiente de regressão linear (b), a variância dos desvios $\left(\mathrm{S}^{2} \mathrm{~d}\right)$ e o coeficiente de determinação $\left(\mathrm{R}^{2}\right)$ permitiram caracterizar, na análise conjunta das três épocas, os genótipos MERINOS"S"/JL"S"/3/BGL"S"/CIN"S"//MUS"S", ICT 8803, IAC 60 e CEP 15, que apresentaram desvio de regressão significativas, o que indica diversidade de rendimento entre épocas. Os genótipos IAC 2 e IAC 60 mostraram-se mais responsivos às condições ambientais $(b>1,0)$, e o CEP 15 , tolerante $(\mathrm{b}<1,0)$ às condições ambientais adversas (Tabela 6).

TABELA 5. Correlação de rendimento de grãos (Rend) com peso hectolítrico ( $\mathrm{PH})$, peso de mil sementes (PMS) e do peso hectolítrico com peso de mil sementes dentro de cada época de semeadura no período 1991-95 em Capão Bonito, SP.

\begin{tabular}{cccc}
\hline Época & Rend. x PH & Rend x PMS & PH x PMS \\
\hline $1^{\mathrm{a}}$ & $0,1263^{\mathrm{ns}}$ & $0,8982^{* *}$ & $0,1214^{\mathrm{ns}}$ \\
$2^{\mathrm{a}}$ & $-0,1135^{\mathrm{ns}}$ & $0,8309^{* *}$ & $0,1599^{\mathrm{ns}}$ \\
$3^{\mathrm{a}}$ & $-0,3119^{\mathrm{ns}}$ & $0,7177^{*}$ & $0,0704^{\mathrm{ns}}$ \\
\hline
\end{tabular}

ns, * e ** Não-significativo e significativo a $5 \%$ e $1 \%$, respectivamente.

TABELA 6. Rendimento médio (kg/ha) de grãos, coeficiente de regressão linear (b), desvios de regressão ( $\left.S^{2} \mathrm{~d}\right)$ e coeficiente de determinação $\left(R^{2}\right)$ dos genótipos de triticale e trigo, avaliados em três épocas de semeadura, no município de Capão Bonito (SP), no qüinqüênio 1991-95.

\begin{tabular}{lcccc}
\hline Genótipos & Rendimento & $\mathrm{b}$ & $\mathrm{S}^{2} \mathrm{~d}$ & $\mathrm{R}^{2}$ \\
\hline IAC 2 & 2551 & $1,3313^{*}$ & $134^{\mathrm{ns}}$ & 96,30 \\
BGL"S"/CIN"S"//MUS"S" & 2470 & 1,2026 & $113^{\mathrm{ns}}$ & 96,47 \\
IAC 3 & 2379 & 1,1569 & $17^{\mathrm{ns}}$ & 98,51 \\
Hare 212 & 2282 & 1,1235 & -1 & 98,60 \\
Ardilla "S" & 2255 & 0,9064 & - & 99,18 \\
BGL"S"/RAM"S" & 2117 & 1,1853 & - & 99,90 \\
MERINOS"S"/JLO"S"/3/BGL"S"/CIN"S"//MUS"S" & 2116 & 0,8819 & $151^{*}$ & 90,77 \\
IAC 1 & 2102 & 1,1033 & - & 99,54 \\
ICT 8803 & 2074 & 0,7457 & $219^{* *}$ & 79,16 \\
IAC 60 (trigo) & 1938 & $1,3584 *$ & $257^{* *}$ & 90,49 \\
IAC 24 (trigo) & 1691 & 0,8728 & - & 98,58 \\
CEP 15 & 1253 & $0,1313 * *$ & $489 * *$ & 2,58 \\
\hline
\end{tabular}

${ }^{1}$ Desvio da regressão menor que o erro experimental.

ns, * e ** Não-significativo e significativo a $5 \%$ e $1 \%$, respectivamente. 


\section{CONCLUSÕES}

1. A melhor época de semeadura é a correspondente ao terceiro decêndio de março, e não deve ser utilizada a do terceiro decêndio de maio.

2. O melhor genótipo de triticale para rendimento de grãos é o IAC 2.

3. Os genótipos IAC 2, BGL"S"/CIN"S"// MUS"S" e o IAC 3 são os melhores na primeira época de semeadura, em rendimento de grãos.

4. Na segunda época, os genótipos Ardilla"S", Hare 212 e ICT 8803, e, na terceira, esses genótipos, acrescidos do MERINOS"S"/JLO"S"/3/BGL"S"/ CIN"S"//MUS"S", equivalem-se aos melhores genótipos em rendimento da primeira época.

5. Os genótipos de trigo, IAC 24 e IAC 60, mais o triticale CEP 15, apresentam os menores rendimentos de grãos, independentemente da época considerada.

6. Os genótipos de triticale de ciclo precoce, médio e tardio apresentam melhores rendimentos de grãos, em relação aos de ciclo superprecoce.

7. O rendimento de grãos associa-se positivamente ao peso de mil sementes nas três épocas de semeadura.

8. A ocorrência dos agentes causais de manchas foliares é mais intensa nas plantas do genótipo de trigo IAC 24 do que nas plantas de triticale, excetuando-se o genótipo de triticale CEP 15, considerado o mais sensível.

9. Os genótipos de triticale IAC 2, BGL"S"/ CIN"S"//MUS"S" e IAC 3 apresentam estabilidade e boa adaptação quanto a rendimento de grãos.

\section{REFERÊNCIAS}

BAIER, A.C. Potencial do triticale no Brasil. In: REUNIÃO BRASILEIRA DE TRITICALE, 4., 1992, Chapecó. Anais. Chapecó: EPAGRI, 1995. p.8-23.

CAMARGO, M.B.P.; CAMARGO, A.P. Representação gráfica informatizada do extrato do balanço hídrico de Thornthwaite \& Mather-1955. Bragantia, Campinas, v.52, n.2, p.169-172, 1993. (Nota)

EBERHART, S.A.; RUSSELL, W.A. Stability parameters for comparing varieties. Crop Science, Madison, v.6, p.36-40, 1966.
FELICIO, J.C.; BARROS, B.C.; FERREIRA FILHO, A.W.P.; CASTRO J.L. de. Ensaios comparativos de cultivares de trigo em diferentes regiões paulistas no biênio 1979/80. Bragantia, Campinas, v.45, n.1,p.114,1986

FELICIO, J.C.; CAMARGO, C.E. de O.; CAMARGO, M.B.P.; CASTRO, J.L. de; BARROS, B. de C. Trigo: três épocas de semeadura em Capão Bonito, SP, no período 1981-85. Bragantia, Campinas, v.47, n. 2, p. $255-275,1988$

FELICIO, J.C.; CAMARGO, C.E. de O.; FERREIRA FILHO, A.W.P.; CASTRO, J.L. de. Comportamento de cultivares de triticale no Estado de São Paulo no período de 1985 a 1987. Pesquisa Agropecuária Brasileira, Brasília, v.25, n.8, p.1143-1149, ago. 1990a.

FELICIO, J.C.; CAMARGO, C.E. de O.; FERREIRA FILHO, A.W.P.; FREITAS, J.G.; PEDRO JUNIOR, M.J. Trigo: épocas de semeadura em Assis (Vale do Paranapanema), SP, no período 1978-82. Bragantia, Campinas, v.50, n.1, p.115-128, 1991

FELICIO, J.C.; CAMARGO, C.E. de O.; PIZZINATTO, A.; CASTRO, J.L.; GALLO, P.B. Comportamento agronômico e avaliação tecnológica de genótipos de triticale no Estado de São Paulo em 1988 a 1989. Pesquisa Agropecuária Brasileira, Brasília, v.28, n.3, p.281-294, mar. 1993.

FELICIO, J.C.; CAMARGO, C.E.O.; SILVÉRIO, J.C.; PEDRO JUNIOR, M.J. Trigo: três épocas de semeadura em Paranapanema, SP, de 1981-1985. Bragantia, Campinas, v.49, n.2, p.371-390, 1990b.

FELICIO, J.C.; LEITE, N. Micronutrientes na forma de óxidos silicatados e chochamento em trigo de várzeas. Pesquisa Agropecuária Brasileira, Brasília, v.17, n.10, p.1417-1421, out. 1982.

KALCKMANN， R.E.; ARRUDA， A.A.G.; HOETGEBAUM, F.; POPA, W.; BALDANZI, G.; GODOY, L.C. de. Regiões de trigo no Brasil 1a aproximação agrícola. Pelotas: Serviço de Informação Agrícola, 1965. 104p. (SIA. Estudos técni$\cos , 28)$.

KOHLI, M.M. El estado actual del triticale, problemas y perspectivas. In: REUNIÃO BRASILEIRA DE TRITICALE, 3., 1989, Cascavel, PR. Anais. Cascavel, OCEPAR, 1989. p.21-51.

Pesq. agropec. bras., Brasília, v.34, n.12, p.2193-2202, dez. 1999 
LUZ, W.C. da. Influência do período de umidificação pósinoculação na reação de cultivares de trigo à mancha foliar (Cochliobolus sativus). In: REUNIÃO NACIONAL DE PESQUISA DE TRIGO, 12., Cascavel, 1982. Resultados de pesquisa. Passo Fundo: Embrapa-CNPT, 1982. p.186-191.

METHA, Y.R. Doenças do trigo e seu controle. São Paulo: Ceres, 1978. 190p.

PIMENTEL-GOMES, F. Curso de Estatística Experimental. Piracicaba: ESALQ, 1970. 348p.
RAIJ, B. van; SILVA, N.M. da; BATAGLIA, O.C.; QUAGGIO, J.A.; HIROCE, R.; CANTARELLA, H.; BELLIZARIO JUNIOR, R.; DECHEN, A.R.; TRANI, P. Recomendações de adubação e calagem para o Estado de São Paulo. Campinas: IAC, 1985. 107p. (IAC, Boletim técnico, 100).

THORNTHWAITE, C.W.; MATHER, J.R. The water balance. Centerton, N.J.: Drexel Institute of Technology, 1955. 104p. (Publications in Climatology, v.8, n.1). 